\title{
Impact of dress on human psychology
}

\section{Garima Singh}

Received: 09.10.2020; Accepted: 22.11.2020

Author for Correspondence:

\section{Garima Singh}

Department of Apparel and

Textile Science, College of

Home Science, Punjab

Agricultural University,

Ludhiana (Punjab) India

Email : gsingh1505@gmail.com
ABSTRACT : Clothes have a strong influence over the way other people perceive us; you may be talented and qualified, but sweatpants at a job interview probably won't communicate your ambition to a potential boss. "The formality of clothing might not only influence the way others perceive a person, and how people perceive themselves, but could influence decision making in important ways through its influence on processing style." Fashion trend today does not give precedence to comforts and practicality. Sometimes the dress, that goes beyond modesty and simplicity, which does not allow someone to sit or walk properly, is attracted by youth. This growing trend of self awareness for one's look has influenced every aspect of generation individual behaviour and is reflected in every sphere starting from social media platforms to real life purchase decisions. Colour can carry important meaning and can have an important impact on people's affect, cognition, and behaviour. Clothes have systematic influence on wearer's psychological processes. Minor clothing manipulations can give rise to significantly different inferences. Even small changes in clothing choice can communicate different information to a perceiver. Dress affects one's ideas about the self(e.g., attitudes, values, beliefs) as well as selfdirected behaviours. This growing trend of self awareness for one's look has influenced every aspect of new generation individual behaviour and is reflected in every sphere starting from social media platforms to real life purchase decisions.

KEY WORDS: Clothing, Cognition, Fashion Trend, Psychological Processes

- HOW TO CITE THIS PAPER : Singh, Garima (2020). Impact of dress on human psychology. Asian J. Home Sci., 15 (2) : 424-428, DOI: 10.15740/HAS/AJHS/15.2/424-428. Copyright@ 2020: Hind AgriHorticultural Society. 